\title{
Isolation and Identification of Amadori Compounds from Miso, White Wine and Saké
}

\author{
Hironaga HASHIBA \\ Noda Institute for Scientific Research, Noda-shi, Chiba-ken, Japan \\ Received March 27, 1978
}

\begin{abstract}
Amadori compounds, one of important factors contributing to oxidative browning of soy sauce, were isolated and identified from miso, white wine and Saké by ion exchange chromatography, gel filtration and partition chromatography. Fructose-leucine, fructoseisoleucine, fructose-valine and fructose-alanine were present in miso, white wine and Saké. Fructose-glycine was identified in miso and Saké, and fructose-proline was found in white wine. Amino-carbonyl reaction was suggested to be involved in oxidative browning of miso, white wine and Saké.
\end{abstract}

It is well known that some brewed products such as miso, white wine and Saké darken during storage in contact with atmospheric oxygen. Kamata' and Motai et al. ${ }^{21}$ studied the interaction between sugars and amino compounds in the browning of miso but the effects of oxygen on the browning remain obscure. Villiers $^{3 /}$ reported the participation of polyphenols in the browning of wine and Tadenuma et $a l^{4}{ }^{4}$ demonstrated an important role of ferrichrome in the oxidative browning of Saké, however, amino-carbonyl reaction in white wine or Saké was not described. Previously, I have suggested that Amadori compounds contribute to the oxidative browning of soy sauce ${ }^{5)}$ and isolated some Amadori compounds from soy sauce. ${ }^{6)}$ Since miso, ${ }^{7,8)}$ white wine ${ }^{9,10)}$ and Saké ${ }^{11,12)}$ contain appreciable amounts of sugars and amino acids, Amadori compounds would be formed in them universally and participate in oxidative browning. Nevertheless, there has been no report that demonstrated the presence of Amadori compounds in these brewed products. In this paper the author identified Amadori compounds in miso, white wine and Saké and suggested the important role of Amadori compounds in oxidative browning.

\section{MATERIALS AND METHODS}

Miso, white wine and Saké. Commercial rice miso (salty, red-tone group, brewed in Nagano-ken, Japan), white wine (brewed in Yamanashi-ken, Japan) and Saké (second grade, brewed from rice, rice koji, alcohol and sugar about 45 days before in Hyogo-ken, Japan) were obtained from the market.

Saline water soluble fraction of miso. Ten grams of miso was mixed with $20 \mathrm{ml}$ of $20 \%$ water solution of sodium chloride. Saline water soluble fraction was obtained by the filtration of the mixture with Toyo filter paper No. 2 .

Measurement of oxidative browning of the saline water soluble fraction of miso, white wine and Saké. The methods were almost the same as previously reported. ${ }^{5}$

Preparation of a cation fraction from miso. Two hundred and fifty grams of miso was mixed with $250 \mathrm{ml}$ of distilled water in a 2-liter beaker. The amounts of Amadori compounds in $250 \mathrm{~g}$ of miso calculated by ferricyanide-reducing value was 25 mmoles as fructoseglycine $(F-G l y)$. Miso and water were kneaded with a wooden pestle, then $500 \mathrm{ml}$ of distilled water was added to the mixture and further kneading was done. After the filtration of the mixture with suction, the filtrate (about $300 \mathrm{ml}$ ) was diluted to 1.5 liters with distilled water and passed over Amberlite $\mathrm{CG}-120\left(\mathrm{H}^{+}\right.$. form, $100 \sim 200 \mathrm{mesh}$ ) packed in a $3.5 \times 50 \mathrm{~cm}$ column. The procedure of the elution of the adsorbed compounds on the resin was according to the method previously described, ${ }^{6}$ that is, after washing the resin with 1 liter of distilled water, adsorbed compounds were eluted with $0.1 \mathrm{~N}$ ammonia, and $20-\mathrm{ml}$ fractions were collected. The ferricyanide-reducing value ${ }^{13}$ ) of each fraction was determined and pale yellow to yellow brown fractions which reduced ferricyanide were pooled. The pooled eluent was designated as a cation fraction from miso. 
Preparation of a cation fraction from white wine and Saké. Six liters of the wine or Saké was passed over Amberlite CG-120 ( $\mathrm{H}^{+}$-form, 100 200 mesh) packed in a $3.5 \times 50 \mathrm{~cm}$ column. The amounts of Amadori compounds in 6 liters of the wine or Saké calculated by ferricyanide-reducing value were about 31 and 4.5 mmoles, respectively. After washing the resin with $500 \mathrm{ml}$ of distilled water, adsorbed compounds were eluted with $0.1 \mathrm{~N}$ ammonia, and $20-\mathrm{ml}$ fractions were collected. The ferricyanide-reducing value of each fraction was determined and pale yellow fractions which reduced ferricyanide were pooled. The pooled eluent was designated as a cation fraction from white wine or Saké.

Preparation of $F I$ from the cation fractions. The cation fraction obtained from $250 \mathrm{~g}$ of miso, 6 liters of wine or Saké was decolorized with charcoal and passed over Amberlite $\mathrm{CG}-120$ ( $\mathrm{H}^{+}$-form, $100 \sim 200$ mesh) packed in a $2.5 \times 50 \mathrm{~cm}$ column. After washing the resin with $500 \mathrm{ml}$ of distilled water, adsorbed compounds were eluted with $0.1 \mathrm{~N}$ ammonia and $15-\mathrm{ml}$ fractions were collected. The ferricyanide-reducing value of each fraction was measured. Figure 1, (a), (b), and (c) show that ferricyanide-reducing substances in miso, white wine and Saké were separated into two groups, designated as F I and F II. The amounts of Amadori compounds in F I and F II from miso determined by ferricyanide-reducing value were 7.0 and 6.0 mmoles as F-Gly, those from white wine were 2.0 and 1.3 mmoles, and those from Saké were 1.0 and 1.2 mmoles, respectively. Figure 1, (a), (b) and (c) were very similar to that obtained with a cation fraction from soy sauce. ${ }^{8)}$ F I from miso, white wine and Saké were nearly colorless but F II were dark brown and some parts of the ferricyanide-reducing value of F II were considered to be due to the brown pigment. ${ }^{14}$ ) The author tried to identify Amadori compounds from $F \mathbf{I}$ in this experiment.

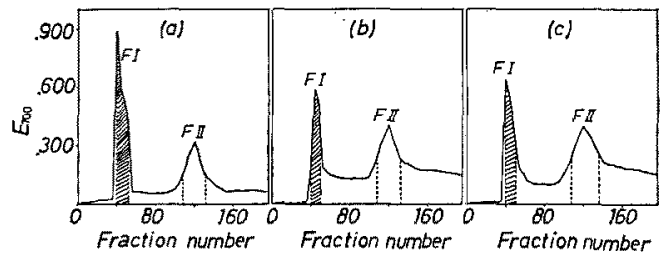

Fig. 1. Effluent Peaks of Ferricyanide-reducing Substances in Cation Fractions of Miso (a), White Wine (b) and Saké (c).

Column size, $2.5 \times 50 \mathrm{~cm}$; fraction volume, $15 \mathrm{ml}$.

Partition chromatography of Amadori compounds with Sephadex G-15. Sephadex G-15 was suspended in a solvent composed of butanol-acetic acid-water (4:1:1, by volume). The suspension was poured into
$2.5 \times 39 \mathrm{~cm}$ or $1.5 \times 50 \mathrm{~cm}$ column. After Sephadex G-15 was packed, the column was washed with 700 $1000 \mathrm{ml}$ of the same solvent. Samples were dissolved in $50 \%$ methanol and applied on the top of the bed and the elution was done with the same solvent composed of butanol, acetic acid and water. Fifteen milliliters or $8 \mathrm{ml}$ of the eluent was collected with a fraction collector, and each fraction was tested by ninhydrin ${ }^{15}$ ) and Somogyi-Nelson's reaction. ${ }^{18)}$ Since the method of Adachi ${ }^{18}$ ) which determines reducing value with potassium ferricyanide was not available in this case because of the interference by butanol, the reducing value was measured by Somogyi-Nelson's reaction.

\section{RESULTS}

\section{Oxidative browning of the saline water soluble} fraction of miso, white wine and Saké

Oxidative browning of miso, white wine and Saké was studied to investigate the correlation between the oxidative browning and Amadori compounds. Table I shows that these three materials exhibited appreciable browning in the presence of oxygen and iron in the similar way as soy sauce and Amadori compounds. This fact implies that Amadori compounds may be contained in these brewed products.

TABLE I. EFFECT OF OXYGEN AND IRON ON THE Oxidative Browning of Saline Water Soluble Fraction of Mrso, WhITE WINE AND SAKÉ

\begin{tabular}{|c|c|c|c|c|}
\hline & \multicolumn{4}{|c|}{ Browning $\left(\Delta E_{440}\right)^{\alpha}$} \\
\hline & \multicolumn{2}{|c|}{ Nonoxidative } & \multicolumn{2}{|c|}{ Oxidative } \\
\hline & $\begin{array}{l}\text { Without } \\
\mathrm{Fe}^{2+}\end{array}$ & $\underset{\mathrm{Fe}^{2+b}}{\text { With }}$ & $\begin{array}{l}\text { Without } \\
\mathrm{Fe}^{2+}\end{array}$ & $\begin{array}{c}\text { With } \\
\mathrm{Fe}^{2+b}\end{array}$ \\
\hline $\begin{array}{l}\text { Saline water } \\
\text { soluble } \\
\text { fraction of miso }\end{array}$ & 0.020 & 0.030 & 0.220 & 0.408 \\
\hline White wine & 0.001 & 0.002 & 0.020 & 0.060 \\
\hline Saké & 0.000 & 0.001 & 0.005 & 0.013 \\
\hline
\end{tabular}

Partition chromatography of Amadori compounds from miso

One hundred and fifty milliliters of F I from $250 \mathrm{~g}$ of miso was concentrated to $10 \mathrm{ml}$ in vacuo below $20^{\circ} \mathrm{C}$ and applied on gel filtration with Sephadex G-10 packed in a $2.6 \times 100 \mathrm{~cm}$ column to remove a little pigment and im- 
purities and 15-ml fractions were collected. Ferricyanide-reducing value of each fraction was determined (only a single symmetrical peak was obtained) and the fractions which reduced ferricyanide were pooled and concentrated to $4 \mathrm{ml}$ below $20^{\circ} \mathrm{C}$ in vacuo. Two milliliters of the concentrated fraction was applied on partition chromatography with a column of $2.5 \times$ $39 \mathrm{~cm}$ and $15-\mathrm{ml}$ fractions were collected. Each fraction was tested by ninhydrin and SomogyiNelson's reaction (Fig. 2). Three substances designated as M-I (fractions No. 10 No. 19), M-II (fractions No. $27 \sim$ No. 30) and M-III (fractions No. 39 No. 43) were obtained. Each substance was dried up in vacuo below $20^{\circ} \mathrm{C}$ and dissolved in $1 \mathrm{ml}$ of $50 \%$ methanol and again applied on partition chromatography with a column of $1.5 \times 50 \mathrm{~cm}$ and $8-\mathrm{ml}$ fractions were collected (Fig. 3). M-I was separated into M-I-1 and M-I-2, however, M-II

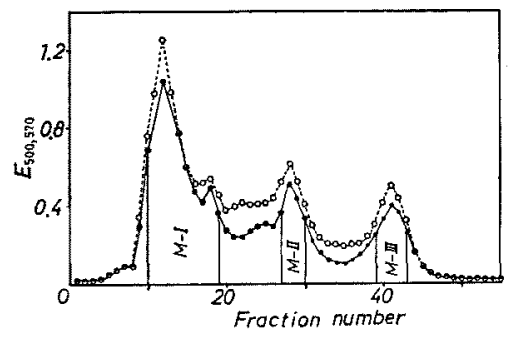

FIG. 2. Partition Chromatography of F I from Miso. Column size, $2.5 \times 39 \mathrm{~cm}$; fraction volume, $15 \mathrm{ml}$; solvent of elution, butanol-acetic acid-water $(4: 1: 1$, by volume). $\bigcirc$, ninhydrin reaction $\left(E_{570}\right)$;, Somogyi-Nelson's reaction $\left(E_{500}\right)$.

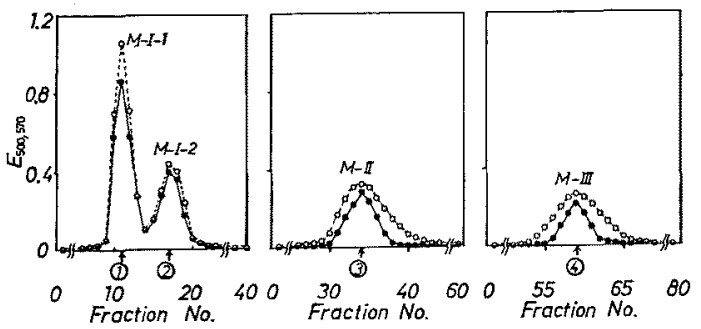

FIG. 3. Partition Chromatography of M-I, M-II and $\mathrm{M}-\mathrm{III}$.

Column size, $1.5 \times 50 \mathrm{~cm}$; fraction volume, $8 \mathrm{ml}$. $O$, ninhydrin reaction $\left(E_{570}\right)$;, Somogyi-Nelson's reaction $\left(E_{300}\right)$. (1), (2), (3) and (4) indicate the eluting position of F-Leu (F-Ile), F-Val, F-Ala and F-Gly, respectively. and M-III gave a single peak, respectively in the case of partition chromatography with the column of $1.5 \times 50 \mathrm{~cm}$.

\section{Partition chromatography of Amadori com-} pounds from white wine and Saké

One hundred milliliters of F I from 6 liters of white wine or $110 \mathrm{ml}$ of F I from 6 liters of Saké were concentrated to $10 \mathrm{ml}$ in vacuo below $20^{\circ} \mathrm{C}$. They were applied on gel filtration with Sephadex G-10 packed in a $2.6 \times$ $100 \mathrm{~cm}$ column to remove a little pigment and impurities and $15-\mathrm{ml}$ fractions were collected. The ferricyanide-reducing value of each fraction was measured and both samples gave a single peak, respectively. The fractions which reduced ferricyanide were pooled and concentrated to $2 \mathrm{ml}$ in vacuo below $20^{\circ} \mathrm{C}$ and applied on partition chromatography with a column of $2.5 \times 39 \mathrm{~cm}$ collecting $15-\mathrm{ml}$ fractions. Each fraction was tested by ninhydrin and SomogyiNelson's reaction. Similar results as in miso (shown in Fig. 2) were obtained also in white wine and Saké. Substances designated as W-I, W-II and W-III were obtained from white wine and those designated as S-I, S-II and S-III were from Saké. Each of six substances was dried up in vacuo below $20^{\circ} \mathrm{C}$ and dissolved in $1 \mathrm{ml}$ of $50 \%$ methanol and again applied on partition chromatography with a column of $1.5 \times$ $50 \mathrm{~cm}$ and $8-\mathrm{ml}$ fractions were collected (Figs. 4 and 5). W-I was separated into W-I-1 and W-I-2, and S-I was separated into S-I-1 and

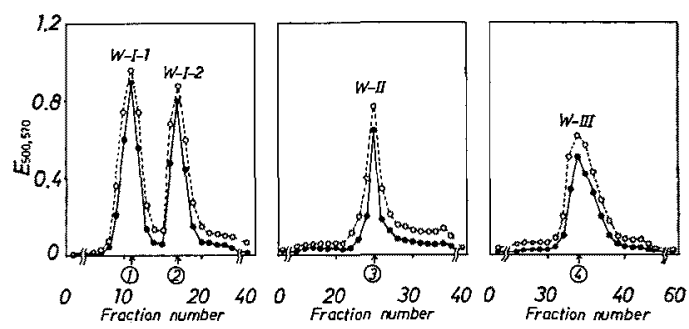

FIG. 4. Partition Chromatography of W-I, W-II and W-III.

Column size, $1.5 \times 50 \mathrm{~cm}$; fraction volume, $8 \mathrm{ml}$. $O$, ninhydrin reaction $\left(E_{570}\right)$;, Somogyi-Nelson's reaction $\left(E_{500}\right)$. (1), (2), (3) and (4) indicate the eluting position of F-Leu (F-Ile), F-Val, F-Pro and F-Ala, respectively. 


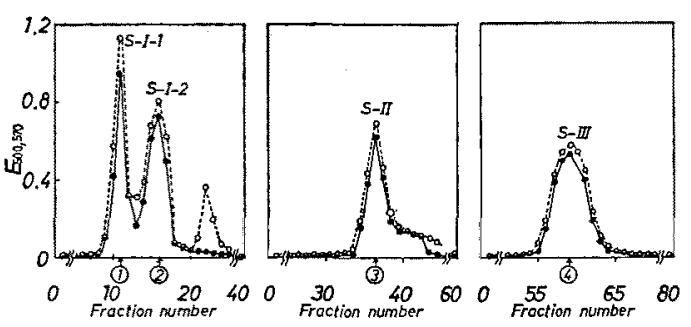

FIG. 5. Partition Chromatography of S-I, S-II and S-III.

Column size, $1.5 \times 50 \mathrm{~cm}$, fraction volume, $8 \mathrm{ml}$. 0 , ninhydrin reaction $\left(E_{570}\right)$; reaction ( $\left.E_{000}\right)$. (1), (2), (3) and (4) indicate the eluting position of F-Leu (F-Ile), F-Val, F-Ala and F-Gly, respectively.

S-I-2. However, W-II, W-III, S-II and S-III gave a single peak, respectively in the case of partition chromatography with the column of $1.5 \times 50 \mathrm{~cm}$.

Identification of the Amadori compounds from miso, white wine and Saké

Substances obtained by the partition chromatography with a column of $1.5 \times 50 \mathrm{~cm}$ was dried in vacuo below $20^{\circ} \mathrm{C}$. Each dried sample was dissolved in $1 \mathrm{ml}$ of water and applied on gel filtration with Sephadex G-10 packed in a $1.5 \times 100 \mathrm{~cm}$ column to remove small amounts of pigment and impurities. Ferricyanidereducing value of each fraction was measured and a single peak was obtained, respectively. The fractions reduced ferricyanide were pooled and lyophilized. The results of amino acid analysis of these substances before and after the hydrolysis with $6 \mathrm{~N} \mathrm{HCl}$ at $120^{\circ} \mathrm{C}$ for $20 \mathrm{~min}$ are shown in Table II. In addition, the results of thin-layer chromatography is shown in Fig.8. The experimental data obtained with the eluting position of the substances in the partition chromatography of Figs. 3, 4, and 5, liberated amino acids in Table II and good agreement of the $R f$ value of the isolated substances and synthesized authentic samples ${ }^{5}$ in both ninhydrin and $\mathrm{KIO}_{4}$-tetrabase tests (Fig. 6) induced the following conclusions: (i) $\mathrm{M}-\mathrm{I}-1$, W-I-1 and S-I-1 are mixtures of fructoseisoleucine (F-Ile) and fructose-leucine (F-Leu); (ii) M-I-2, W-I-2 and S-I-2 are fructose-valine
(F-Val); (iii) W-II is fructose-proline (F-Pro); (iv) M-II, W-III and S-II are fructose-alanine (F-Ala); (v) M-III and S-III are F-Gly.

M-I-2 could only be crystallized from ethanol (about $180 \mathrm{mg}$ from $2 \mathrm{~kg}$ of miso): $\mathrm{mp} 150^{\circ} \mathrm{C}$ dec; $[\alpha]_{\mathrm{D}}^{20}-35.0^{\circ}(c=1$, water $)$ Anal. Calcd. for $\mathrm{C}_{11} \mathrm{H}_{21} \mathrm{NO}_{7}: \mathrm{C}, 47.3 ; \mathrm{H}, 7.58 ; \mathrm{N}, 5.01$; neut. equiv. 279.3. Found: $\mathrm{C}, 47.24 ; \mathrm{H}, 7.46$; N, 4.79 ; neut. equiv. 279.0.

Each concentration of the identified Amadori compounds was estimated by the hydrolysis of

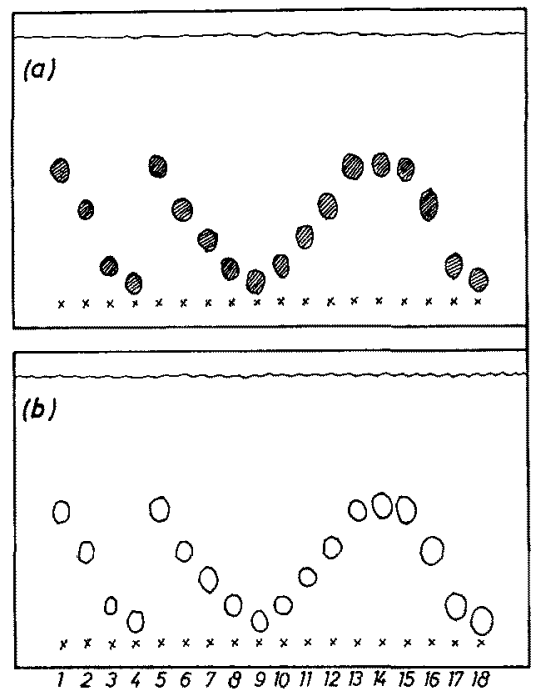

Fig. 6. Thin-layer Chromatography of Amadori Compounds.

Solvent, butanol-acetic acid-water $(4: 1: 1$, by volume). Detection reagent: (a), ninhydrin; (b), $\mathrm{KIO}_{4^{-}}$ tetrabase. $1, \mathrm{M}-\mathrm{I}-1 ; 2, \mathrm{M}-\mathrm{I}-2 ; 3, \mathrm{M}-\mathrm{II} ; 4, \mathrm{M}-\mathrm{III}$; 5, W-I-1; 6, W-I-2; 7, W-II; 8, W-III; 9, F-Gly; 10, F-Ala; 11, F-Pro; 12, F-Val; 13, F-Ile; 14, F-Leu; 15, S-I-1; 16, S-I-2; 17, S-II; 18, S-III.

Table II. Hydrolysis of AMAdori Compounds From Miso, White Wine and SaKé

\begin{tabular}{lrl}
\hline Amadori compounds & $\begin{array}{c}\text { Position of } \\
\text { emergence }^{a}\end{array}$ & $\begin{array}{c}\text { Liberated } \\
\text { amino acid(s) } \\
\text { by hydrolysis }\end{array}$ \\
\hline M-I-1, W-I-1, S-I-1 & Asp Thr & Ile, Leu \\
M-I-2, W-I-2, S-I-2 & Before Asp & Val \\
W-II & Before Asp & Pro \\
M-II, W-III, S-II & Before Asp & Ala \\
M-III, S-III & Before Asp & Gly \\
\hline
\end{tabular}

a Position of emergence in Hitachi KLA-5 amino acid analyzer. 
Table III. Concentration of Amadori Compounds in Miso, WHITE Wine aNd SAKé

\begin{tabular}{lcccccc}
\hline & \multicolumn{7}{c}{ Concentration of Amadori compounds ${ }^{a}$} \\
\cline { 2 - 7 } & F-Gly & F-Ala & F-Pro & F-Val & F-Ile & F-Leu \\
\hline Miso & 0.2 & 0.5 & - & 1.3 & 1.3 & 1.7 \\
White wine & - & 0.015 & 0.016 & 0.012 & 0.005 & 0.007 \\
Saké & 0.003 & 0.004 & - & 0.006 & 0.004 & 0.005 \\
\hline
\end{tabular}

a Concentration is mmoles $/ \mathrm{kg}$ of material.

F I from miso, white wine and Saké according to the same method as used in soy sauce ${ }^{6}$ (Table III).

\section{DISCUSSION}

Since miso, white wine and Saké contain many kinds of amino acids, they may also contain many kinds of Amadori compounds derived from those amino acids. However, only six Amadori compounds from neutral amino acids could be identified in this experiment. The concentration of the identified Amadori compounds in these brewed materials estimated by the hydrolysis of F I are not so accurate. But it can be considered that proline, glycine, alanine, valine, isoleucine and leucine produced by the hydrolysis of F I were liberated from Amadori compounds and not from peptides, because FI was suggested to contain no peptides consisting of these amino acids. ${ }^{6 !}$

The total concentrations of the isolated Amadori compounds in miso, white wine and Saké were so low $(5.0,0.055$ and 0.022 mmoles per $\mathrm{kg}$, respectively in Table III) that the effect of these Amadori compounds on the oxidative browning seems to be small. However, the amounts of Amadori compounds in these brewed materials were larger than those of the isolated Amadori compounds, that is, the total concentrations of Amadori compounds in F I from miso, white wine and Saké calculated by ferricyanide-reducing value as F-Gly were $28,0.33$ and 0.17 mmoles per $\mathrm{kg}$, respectively. Therefore, it is suggested that Amadori compounds would give effects on the oxidative browning of these brewages.

Acknowledgements. The author expresses his sincerest thanks to Profs. M. Fujimaki and H. Kato for their kind guidance throughout this work. His thanks are due to Drs. M. Mogi, N. Iguchi, D. Fukushima and I. Koshiyama for their encouragement. Thanks are also due to Dr. H. Mori for help in preparation of this manuscript.

\section{REFERENCES}

1) H. Kamata, J. Soc. Brew., Jpn, 58, 956 (1963).

2) H. Motai and S. Inoue, Nippon Nôgeikagaku Kaishi, 48, 579 (1974).

3) J. P. De Villiers, Am. J. Enol. Vitic., 12, 25 (1961).

4) M. Tadenuma and S. Sato, Agric. Biol. Chem., 31, 1482 (1967)

5) H. Hashiba, J. Agric. Food Chem., 24, 70 (1976).

6) H. Hashiba, Agric. Biol. Chem, 42, 763 (1978).

7) A. Matsushita, Nippon Nôgeikagaku Kaishi, 44, 51 (1970).

8) G. Tamura, J. Kirimura, H. Hara and K. Sugimura, ibid., 26, 483 (1952).

9) M. A. Amerine, H. W. Berg and W. V. Cruess, Technology of Wine Making, p. 114 (1972).

10) K. Otsuka, S. Imai and K. Aiba, Agric. Biol. Chem., 28, 375 (1964).

11) K. Asou, K. Shibazaki and F. Yamauchi, $J$. Ferment. Technol, 32, 47 (1954).

12) M. Hara, J. Soc. Brew., Jpn, 61, 1088 (1966).

13) S. Adachi, Nippon Nôgeikagaku Kaishi, 32, 313 (1958).

14) H. Hashiba, ibid., 47, 727 (1973).

15) H. Rosen, Arch. Biochem. Biophys., 67, 10 (1957).

16) N. Nelson, J. Biol. Chem., 153, 375 (1944). 